\title{
Mechanical Properties and Microstructure Evolution of Aluminum Alloy Tubes with Normal Gradient Grain Under Biaxial Stress
}

\author{
Yang CAl ( 108caiyang@163.com ) \\ Harbin Institute of Technology \\ Xiaosong Wang \\ Harbin Institute of Technology
}

\section{Research Article}

Keywords: Gradient grain, Biaxial stress, Aluminum alloy, Microstructure

Posted Date: June 4th, 2021

DOl: https://doi.org/10.21203/rs.3.rs-546223/v1

License: (c) (1) This work is licensed under a Creative Commons Attribution 4.0 International License. Read Full License

Version of Record: A version of this preprint was published at The International Journal of Advanced Manufacturing Technology on January 13th, 2022. See the published version at https://doi.org/10.1007/s00170-021-08412-5. 


\section{Abstract}

Grain size gradient materials are a type of new structural material with the advantages of both coarse and fine grains. To study the effect of normal gradient grain on the mechanical properties and microstructure of aluminum alloy tube during hydroforming, the normal gradient grain distribution of the outer fine and inner coarse grains was obtained using spinning and annealing methods, and the biaxial stress was acquired using hydraulic bulging experiments. The thickness of the outer refined area was 105,470 , and $570 \mu \mathrm{m}$, respectively, where the grain size was refined to within $50 \mu \mathrm{m}$. Under biaxial stress, the tensile strength of the tube was 79,89 , and $106 \mathrm{MPa}$, the maximum expansion rates were $18 \%, 17 \%$, and $10 \%$, and the work-hardening indexes were $0.19,0.20$, and 0.17 , respectively. The gradient grain tube with a refined thickness of $470 \mu \mathrm{m}$ exhibited both strength and plasticity and was suitable for the hydroforming of aluminum alloy tubular parts. With increasing refined grain area, the density of the low angular grain boundary increased and make the chance of stitching dislocation increased in the process of intracranular deformation. However, the increase in the refined region weakened the deformation coordination, leading to a decrease in plasticity.

\section{Introduction}

To reduce the energy consumption of vehicles and realize resource conservation and the more efficient use of energy, there is an urgent need for lightweight structural parts in the aerospace and automotive fields. Hydroformed aluminum alloy tube parts can simultaneously meet the needs of lightweight and structurally lightweight aerospace parts[1][2], often used in densely arranged and complex-shaped tubes in aircraft or rocket power systems[3][4]. However, aluminum alloys often have "surface orange peel" defects during hydroforming. This defect is because of the fact that the surface grains of the aluminum alloy exceed a certain size, with macroscopic surface roughening occurring after plastic deformation, which not only affects the appearance of the component, but also affects its performance[5], such as its weldability and fatigability[6].

Gradient grain structure materials can solve these problems[7][8]. The surface roughness is linearly related to the surface grain size when aluminum alloy is subjected to plastic deformation[9][10]. The surface layer of the gradient grain structure has a fine-grained structure, so it has exhibits better plastic deformation ability and deformation uniformity than that of a coarse-grained structure. Moreover, it exhibits better surface properties[11], and "surface orange peel" defects can be successfully avoided. The structure-other than the surface layer of the gradient structure material-maintains the initial coarsegrained structure. This combination of grain gradients may result in the overall material having higher strength and better plasticity[12]. Because of the existence of a strain gradient in the microstructure and changes in stress state from geometrical dislocations in it, the generation of dislocations and their incoordination with each other produce additional deformation hardening[13][14], and its yield strength is much higher than the sum of individual gradient layers[15][16]. This mechanical incompatibility also produces a high reverse stress, which helps to improve strength and ductility[17]. 
The normal gradient grain tube is applied to hydroforming, although a gradient grain tube with fine surface grain can significantly improve the surface performance of the tube[18]. However, changes in the mechanical properties depend on the gradient grain distribution and force state. The stress state of the tube during hydroforming is complicated, as most areas are in a biaxial stress state. Conventional tube mechanical property test methods-such as uniaxial tensile or circumferential tensile tests-can only reveal the mechanical properties of the tube in the axial or circumferential directions but cannot show the comprehensive mechanical properties of the tube during hydroforming. Consequently, the tube bulging test method, which involves passing a high-pressure liquid into the tube to make the tube bulge under the action of biaxial stress, is used. The obtained stress-strain relationship directly describes the hydroforming ability of the tube; thus, the tube bulging test method has gradually become an in-depth research topic[19][20].

This study examined the effect of normal grain gradient distribution on tube bulging performance and microstructure evolution. First, aluminum alloy tubes with normal gradient grains were obtained by spinning heat treatment, and the mechanical properties of the biaxial stress state were measured using a hydraulic bulging test. The effect of the normal gradient grain on the mechanical properties under biaxial stress was studied, and the microscopic evolution of the normal grain gradient structure under the biaxial stress state was revealed. The findings afford a theoretical basis for the application of aluminum alloy tubes in the hydroforming of tubular parts in the aerospace field.

\section{Experimental Procedure}

\subsection{Materials and Bulging Process}

The initial material was a 6063-T4 aluminum alloy extruded tube, with an outer diameter of $78 \mathrm{~mm}$ and a wall thickness of $3.5 \mathrm{~mm}$. Fig. 1 shows the experimental procedure. Fig. 1(a) shows the spinning diagram, where a large plastic deformation was carried out on the outer surface of the tube through a double roller horizontal spinning machine at $25^{\circ} \mathrm{C}$. The wall thickness of each pass was reduced by 0.25 $\mathrm{mm}$, and after four rounds of thinning the actual outer diameter of the final tube was $76 \mathrm{~mm}$, the actual wall thickness was $2.5 \mathrm{~mm}$, and the spinning thinning amount was $28.57 \%$. Fig. 1(b) shows a schematic diagram of the annealing process. The axial direction of the tube is denoted as $A D$, the transverse direction as TD, and the normal direction as ND. To obtain tubes with normal gradient grains of outer fine and inner coarse grains along the thick direction, the spinning tubes were annealed at 350,400, and 450 ${ }^{\circ} \mathrm{C}$, respectively. The annealing time was $1 \mathrm{~h}$. The tubes were taken out of the furnace, cooled to $260^{\circ} \mathrm{C}$, and then air-cooled. Fig. 1(c) shows a diagram of the tube bulging process. The two ends of the tube were fixed using an annular fixing block, the tube was sealed with a rigid punch, and a high-pressure fluid was passed through to cause the tube to bulge until it burst.

During the bulging process, the instantaneous internal pressure $\mathrm{p}$ and the bulging height $\mathrm{h}$ were measured using a sensor, and the equivalent stress-strain curve of the tube bulging could be obtained (by measuring the wall thickness $t_{0}$ and $t_{p}$ before and after bulging) [13][14]. The yield strength, tensile 
strength, expansion, $K$ value, and $n$ value of the tube could be obtained from the stress-strain curve of the tube bulging process. We set the length-diameter ratio $L / D$ of the bulged length to be 1.5 , and calculated the length $L$ of the bulged length to be $117 \mathrm{~mm}$.

\subsection{Microstructural Characterization}

The microstructure was acquired by electron backscatter diffraction (EBSD) using a Quanta 200 FEG operated at $20 \mathrm{KV}$ with a $5.5 \mu \mathrm{m}$ step size. Specimens for EBSD analysis were prepared by mechanical grinding and electropolishing in an electrolyte containing $20 \%$ perchloric acid in alcohol at a temperature of approximately $-20^{\circ} \mathrm{C}$ and a voltage of $25 \mathrm{~V}$ for $50 \mathrm{~s}$.

\section{Results And Discussion}

\subsection{Microstructure Characteristics of Tube with Gradient Grain}

Fig. 2 shows the transverse microstructure grain size distribution of the tube. Figs. 2(a)-(c) show the microstructures of the spinning tube after annealing and holding at 450,400 , and $350{ }^{\circ} \mathrm{C}$, respectively, for $1 \mathrm{~h}$, in the annealed state. Fig. 2(d) shows the initial thickness of the 6063-T4 aluminum alloy tube microstructure. The grain size distribution of the initial tube microstructure was relatively uniform, and the microstructure of the spin-annealed tube exhibited a gradient distribution. Thus, the grains closer to the outer surface of the tube are thinner, whereas the sizes of those closer to the inner surface of the tube are comparable to the initial tube size.

Fig. 2(e) shows the grain size distribution of the initial tube and the gradient grain tube along the thickness direction. The grain size of the initial tube along the normal direction was between $50-110 \mu \mathrm{m}$, and the distribution was relatively uniform; the zone with a thickness grain size less than the initial thickness grain size minimum value of $50 \mu \mathrm{m}$ is considered to be the refining zone. When annealed at $450^{\circ} \mathrm{C}$ for $1 \mathrm{~h}$, the grain size near the outer surface of the tube was approximately $40 \mu \mathrm{m}$. The fine grain region was $105 \mu \mathrm{m}$ from the surface to the outer surface. The grain size beyond $500 \mu \mathrm{m}$ near the outer surface exceeded the grain size of the initial tube. Abnormal grain growth may have occurred because of the high annealing temperature or long holding time. The grain size of the tube annealed at $400{ }^{\circ} \mathrm{C}$ for $1 \mathrm{~h}$ was approximately $25 \mu \mathrm{m}$ from the outer surface. The fine grain region was from the surface to $470 \mu \mathrm{m}$ from the outer surface, and the grain size was similar to that of the initial tube beyond $500 \mu \mathrm{m}$ from the outer surface. The grain size of the tube annealed at $350^{\circ} \mathrm{C}$ for $1 \mathrm{~h}$ was approximately $20 \mu \mathrm{m}$ from the outer surface. The fine grain region was from the surface to $570 \mu \mathrm{m}$ from the outer surface, and the grain size was similar to that of the initial tube beyond $760 \mu \mathrm{m}$ from the outer surface. Therefore, the spinning tubes were annealed at 400 and $350^{\circ} \mathrm{C}$, and the grain size was refined to $50 \mu \mathrm{m}$ with a fine thickness of $470 \mu \mathrm{m}$ and $570 \mu \mathrm{m}$, respectively. 


\subsection{Mechanical Properties Under Biaxial Stress}

Bulging experiments on three types of normal gradient grain tubes were carried out, and the true stressstrain curves and mechanical properties were obtained under the biaxial stress state. Fig. 3(a) shows an image after the bulging of the normal gradient grain tube. The maximum expansion rate of the bulging tube was measured-the gradient grain tube with a refined thickness of $105 \mu \mathrm{m}$ had the largest expansion rate of $18 \%$; the gradient grain tube with a refined thickness of $470 \mu \mathrm{m}$ had an expansion rate of $17 \%$; and the gradient grain tube with a refined thickness of $570 \mu \mathrm{m}$ has the smallest maximum expansion rate of $10 \%$. The larger the refinement thickness of the gradient grain tube, the poorer is the plasticity and the lower is the expansion rate.

Fig. 3(b) shows the true stress-strain curves, and Fig. 3(c) shows the effect of normal gradient grains on the mechanical properties of the tubes. The gradient grain tubes with refined thicknesses of 105,470 , and $570 \mu \mathrm{m}$ exhibited yield strengths of 60,68 , and $86 \mathrm{MPa}$, tensile strengths of 79, 89, and $106 \mathrm{MPa}$, and work-hardening indexes of $0.19,0.20$, and 0.17 , respectively. For a normal gradient grain tube with fine outside and coarse inside grains, the greater the thickness, the higher is the strength of the tube; the lower the work-hardening index, and the poorer is the ductility.

In summary, the strength of the tube with a refined thickness of $105 \mu \mathrm{m}$ was too low, and the maximum expansion rate of the tube with a refined thickness of $570 \mu \mathrm{m}$ was just $10 \%$, which was too poor in terms of plasticity. Therefore, a tube with a refined thickness of $470 \mu \mathrm{m}$ and which exhibited both strength and plasticity would be more suitable for the hydroforming of aluminum alloy tubular parts.

\subsection{Microstructure Evolution}

Fig. 4 shows the kernel average misorientation (KAM) and distribution of misorientation of the normal gradient grain tubes at an equivalent strain of $12 \%$. Figs. $4(\mathrm{a}-\mathrm{c})$ show the KAM and grain boundary distributions of the microstructure of the tubes with a refined thickness of 105,470 , and $570 \mu \mathrm{m}$, respectively. Different colors represent the different KAM values. The larger the KAM value, the greater is the degree of local deformation. The blue area represents the smallest degree of plastic deformation, where no plastic deformation occurs. The green area represents less plastic deformation, the yellow area represents a greater degree of plastic deformation, and the red area represents the greatest degree of plastic deformation. At the area bulged to an equivalent strain of $12 \%$, the sum of the proportional scores of red, yellow, and orange in Figs. $4(\mathrm{a}-\mathrm{c})$ were $0.172,0.219$, and 0.284 , respectively. This shows that the degree of deformation was most uniform for the tube with a refined thickness of $105 \mu \mathrm{m}$ during bulging. However, the deformation degree of the tube with a refined thickness of $470 \mu \mathrm{m}$ was more uniform. The degree of deformation was concentrated for the tube with a refined thickness of $570 \mu \mathrm{m}$, and the deformation coordination was poor-that is, the greater the refined thickness, the worse is the plasticity.

Observing the change in the number of grain boundaries in the figure, the black line represents the largeangle grain boundary $\left(15-180^{\circ}\right)$-that is, the grain boundary-and the white lines represent small-angle 
grain boundaries $\left(2-15^{\circ}\right)$-that is, the intragranular dislocations. Fig. 4(d) is a statistical diagram of the orientation angle between the grains of the microstructure. In the same area which bulged at the equivalent strain of $12 \%$, the proportions of small-angle grain boundaries were $0.41,0.48$, and 0.54 for the refined thicknesses of 105,470 , and $570 \mu \mathrm{m}$, respectively. The greater the proportion of small-angle grain boundaries, the more opportunities for pinning dislocations during intragranular deformation, the higher the strength of the tube. As a result, the higher the strength, the poorer is the plasticity, as in Fig. 4(a-c).

\section{Conclusion}

The normal gradient grain distribution was obtained and the mechanical properties and microstructure evolution of aluminum alloy tubes with normal gradient grain under biaxial stress was studied. The following conclusions were reached:

1) Spinning $6063-\mathrm{T} 4$ aluminum alloy tubes with $28.57 \%$ thinning, were annealed at 450,400 , and $350^{\circ} \mathrm{C}$ for $1 \mathrm{~h}$ to obtain normal gradient grain aluminum alloy tubes. The thicknesses of the refined region with a grain size of less than $50 \mu \mathrm{m}$ were 105,470 , and $570 \mu \mathrm{m}$, respectively. The grains in the non-refined area of the annealed tubes at $450{ }^{\circ} \mathrm{C}$ were abnormally grown, the non-refined areas of the other two tubes maintaining the same grain size as the initial tube.

2) Normal gradient grain aluminum alloy tubes with refinement zone thicknesses of 105, 470, and 570 $\mu \mathrm{m}$, and tensile strengths of 79,89 , and $106 \mathrm{MPa}$, respectively, exhibited maximum expansions of $18 \%$, $17 \%$, and $10 \%$, and work-hardening indexes of $0.19,0.20$, and 0.17 , respectively. Among them, the tube with a thickness of $470 \mu \mathrm{m}$ in the refined zone obtained by annealing at $400^{\circ} \mathrm{C}$ exhibited both strength and plasticity, making it suitable for the hydroforming of aluminum alloy tubes.

3) The KAM diagram of the microstructure of the normal gradient grained tube shows the normal gradient grain aluminum alloy tubes-with refined area thicknesses of 105,470 , and $570 \mu \mathrm{m}$-to have successively worsened their deformation coordination, resulting in poor plasticity. However, the density of small-angle grain boundaries successively increased; the more opportunities for pinning dislocations during intragranular deformation, the higher is the strength.

\section{Declarations}

Code availability Not applicable.

Author contribution Yang Cai (experimental analysis); Xiaosong Wang (language instruction).

Funding The authors received financial support from the Nature Science Foundation of Heilongjiang Province (LH2020E125).

Data availability Not applicable. 
Ethical approval The article follows the guidelines of the Committee on Publication Ethics (COPE) and involves no studies on human or animal subjects.

Consent to participate Not applicable. The article involves no studies on humans.

Consent to publish Not applicable. The article involves no studies on humans.

Competing interests The authors declare no competing interests.

\section{References}

1. Shijian Y, Zhubin H, Gang L, et al. New developments in theory and processes of internal high pressure forming [J]. The Chinese Journal of Nonferrous Metals, 2011, 21(10): 2523-2533.

2. Shijian $Y$, Wei $L$, Guofeng $W$, et al. Advance in fluid pressure forming of complex light metal thinwalled components[J]. Aerospace Shanghai, 2019, 36(02):35-41.

3. Dong Jie S, Yu Z, Lian Bo W, et al. Application status of the automotive subframe of aluminum alloy[J]. Light Alloy Fabrication Technology, 2015.8(43): 16-19.

4. Zhao J, Deng Y, Tang J, et al. Effect of gradient grain structures on corrosion resistance of extruded Al-Zn-Mg-Cu alloy[J]. Journal of Alloys and Compounds, 2020, 832:154911.

5. Cheng $C$, Wan M, Meng B, et al. Characterization of the microscale forming limit for metal foils considering free surface roughening and failure mechanism transformation[J]. Journal of Materials Processing Technology, 2019, 272: 111-124.

6. Xiaofang Z. Research status of surface roughening during plastic deformation[J]. Surface Technology, 2012, 41(1): 99-101.

7. Haofei Z. Progress in mechanical properties, deformation mechanisms and multiscale simulations of gradient nanostructured metals[J]. Chinese Journal of Solid Mechanics, 2019, 40(3): 193-212.

8. Ke L. Gradient Nanostructured Materials[J]. Acta Metallurgica Sinica, 2015, 1(1): 1-10.

9. Wang $\mathrm{S}$, Zhang $\mathrm{S}$, Song $\mathrm{H}$, et al. Surface roughness improvement of the bent thin-walled copper tube by controlling the microstructure and texture components[J]. Procedia Manufacturing, 2020, 50: 613617.

10. Panin A V, Kazachenok M S, Romanova V A, et al. Strain-Induced Surface Roughening in Polycrystalline VT1-0 Titanium Specimens under Uniaxial Tension[J]. Physical Mesomechanics, 2018, 21(3):249-257.

11. Kozlov E V, Zhdanov A N, Koneva N A. Deformation mechanisms and mechanical properties of nanocrystalline materials[J]. physical mesomechanics, 2008, 11(1-2):42-50.

12. Wu X L, Yang M X, Yuan F P, et al. Combining gradient structure and TRIP effect to produce austenite stainless steel with high strength and ductility[J]. Acta Materialia, 2016, 112: 337-346.

13. Peng X L, Huang G Y, Bargmann S. Gradient Crystal Plasticity: A Grain Boundary Model for Slip Transmission[J]. Materials, 2019, 12(22): 1-23. 
14. Wei D, Han Q, Cai L, et al. Strengthening iron wires through gradient grain structure[J]. Materials Characterization, 2021, 1(171): 110821.

15. J. Wei, Y.Q. Li, L.C. Zhu, Y. Liu, X.Q. Lei, G. Wang, Y.X. Wu, Z.L. Mi, J.B. Liu, H.T. Wang, H.J. Gao, Evading the strength-ductility trade-off dilemma in steel through gradient hierarchical nanotwins, Nature Communications. 2014, 2: 3580.

16. Wu X, Yang M, Li R, et al. Plastic accommodation during tensile deformation of gradient structure. Science China Materials, 2021.1: 1-11.

17. Yang $M$, Pan $Y$, Yuan $F$, et al. Back stress strengthening and strain hardening in gradient structure[J]. Materials Research Letters. 2016, 4(3): 1-7.

18. Yang C, Xiaosong W, Shijian Y. Surface Roughening Behavior of 6063 Aluminum Alloy during Bulging by Spun Tubes[J]. Materials, 2017, 10(3):299.

19. He Z, Yuan S, Lin Y, et al. Analytical model for tube hydro-bulging test, part I: Models for stress components and bulging zone profile[J]. International Journal of Mechanical Sciences. 2014, 87(4): 297-306.

20. He Z, Yuan S, Lin Y, et al. Analytical model for tube hydro-bulging tests, part II: Linear model for pole thickness and its application[J]. International Journal of Mechanical Sciences, 2014, 87(1):307-315.

\section{Figures}




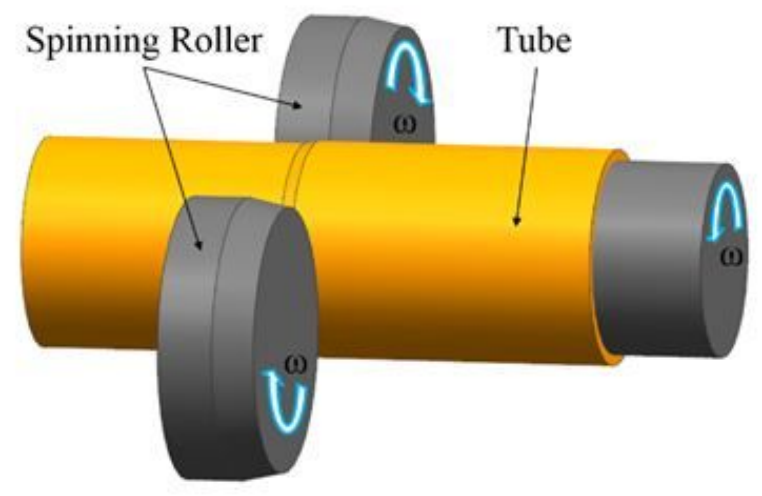

(a) Spinning

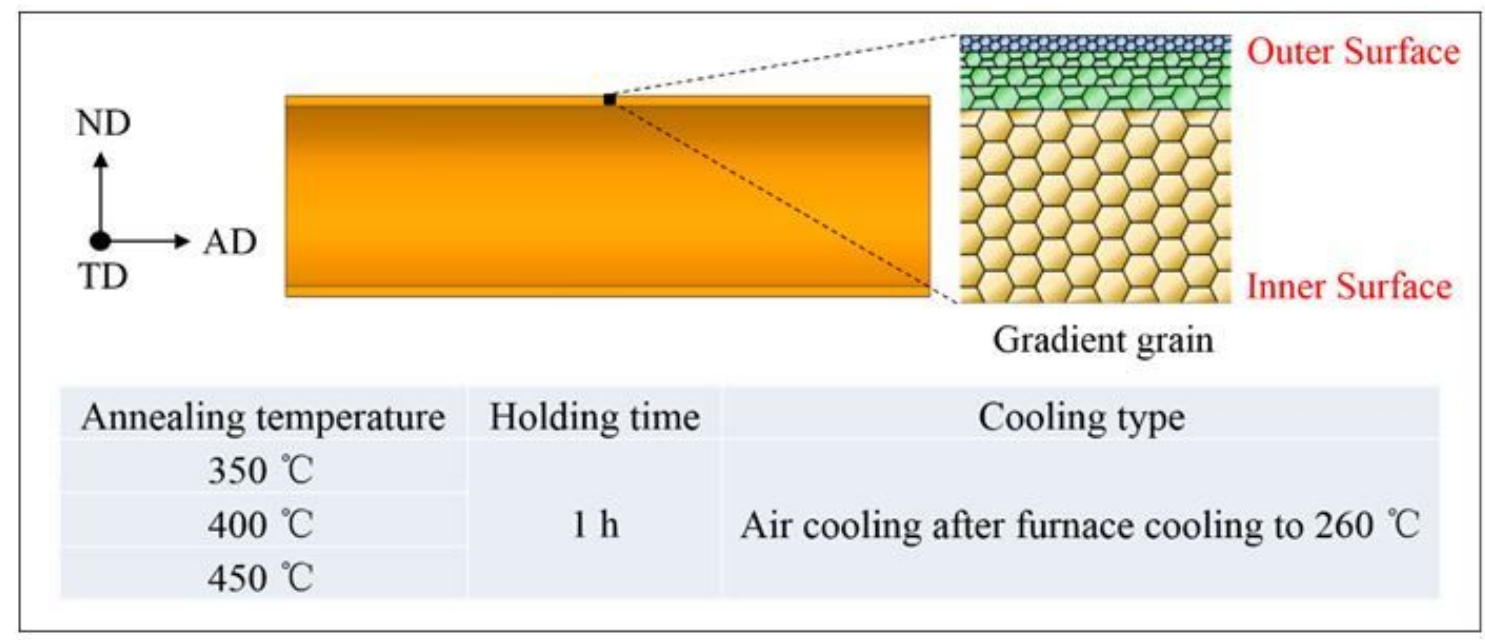

(b) Annealing

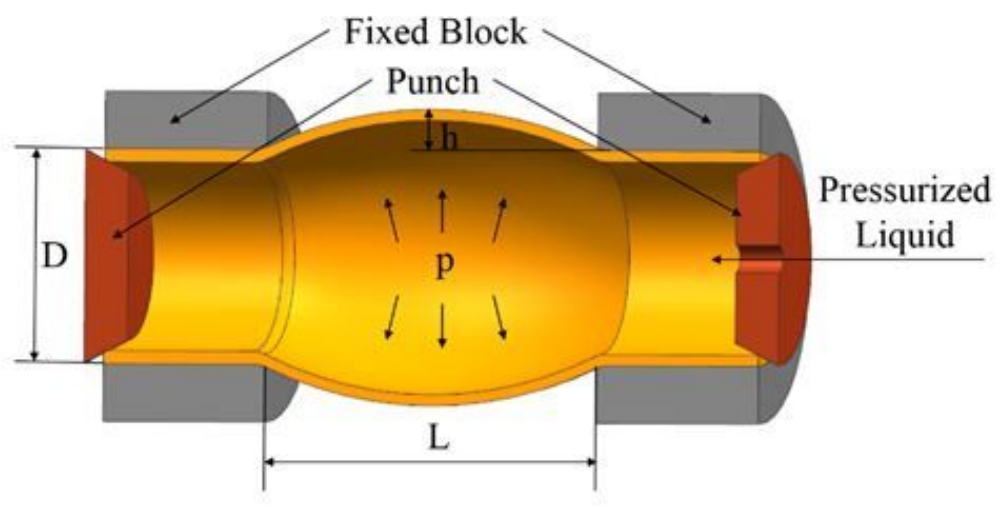

(c) Bulging

Figure 1

Experimental procedure. 


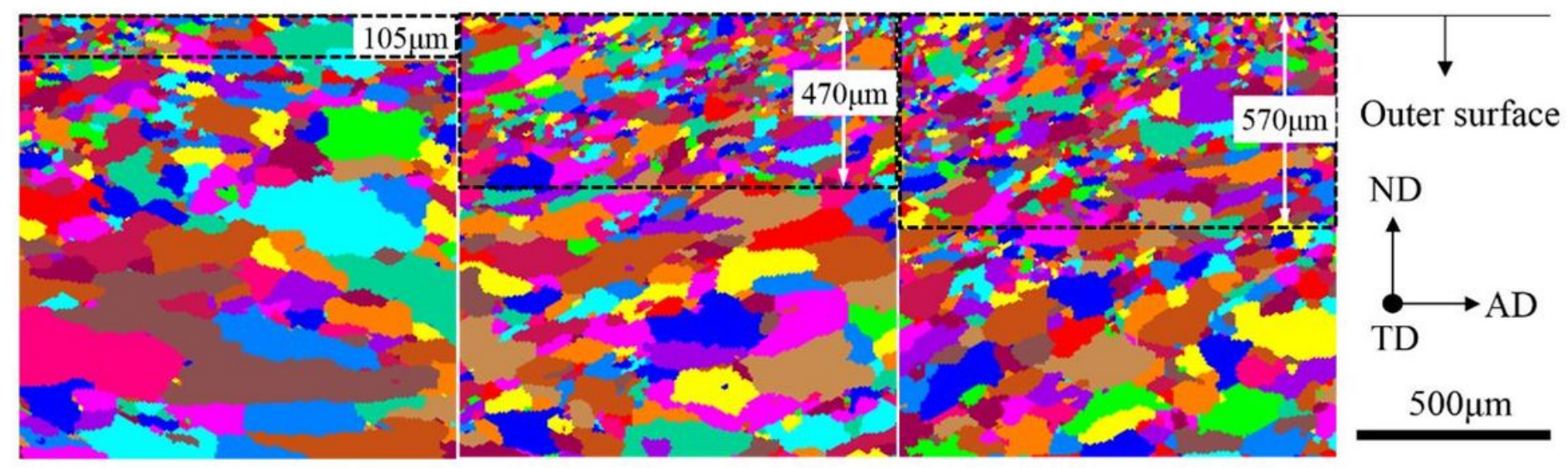

(a) Annealed at $450^{\circ} \mathrm{C}$

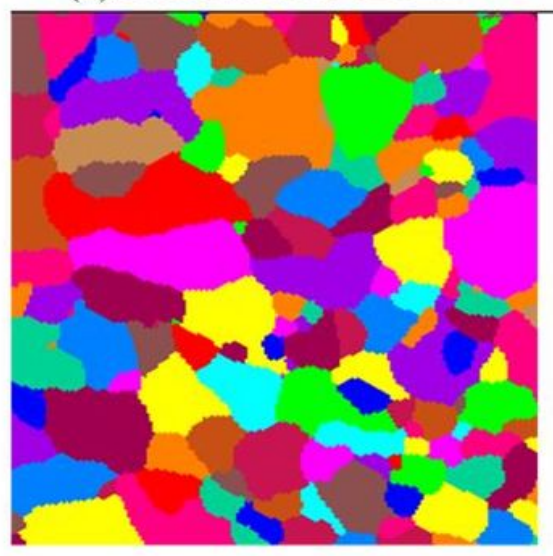

(d) Initial tube (b) Annealed at $400^{\circ} \mathrm{C}$

(c) Annealed at $350^{\circ} \mathrm{C}$

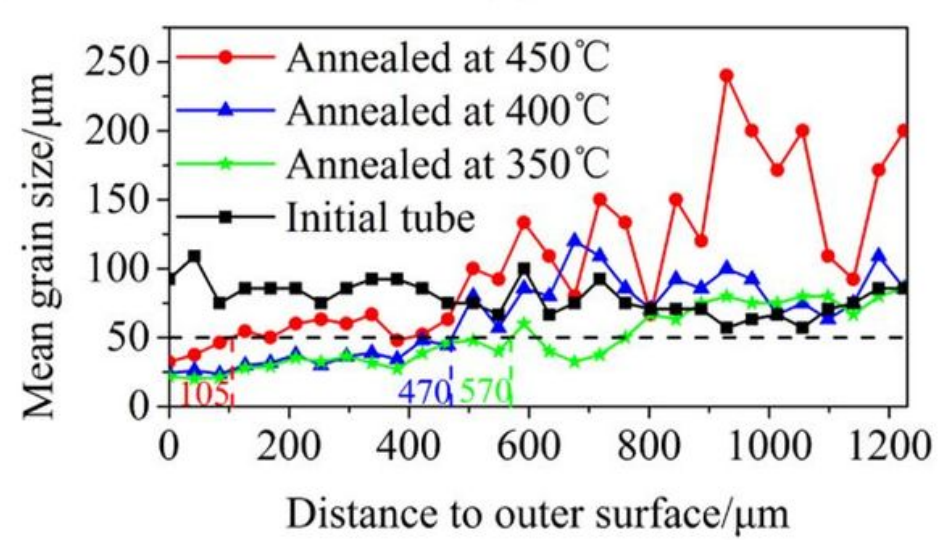

(e) Grain size distribution

Figure 2

Transverse microstructure and grain size distribution. 


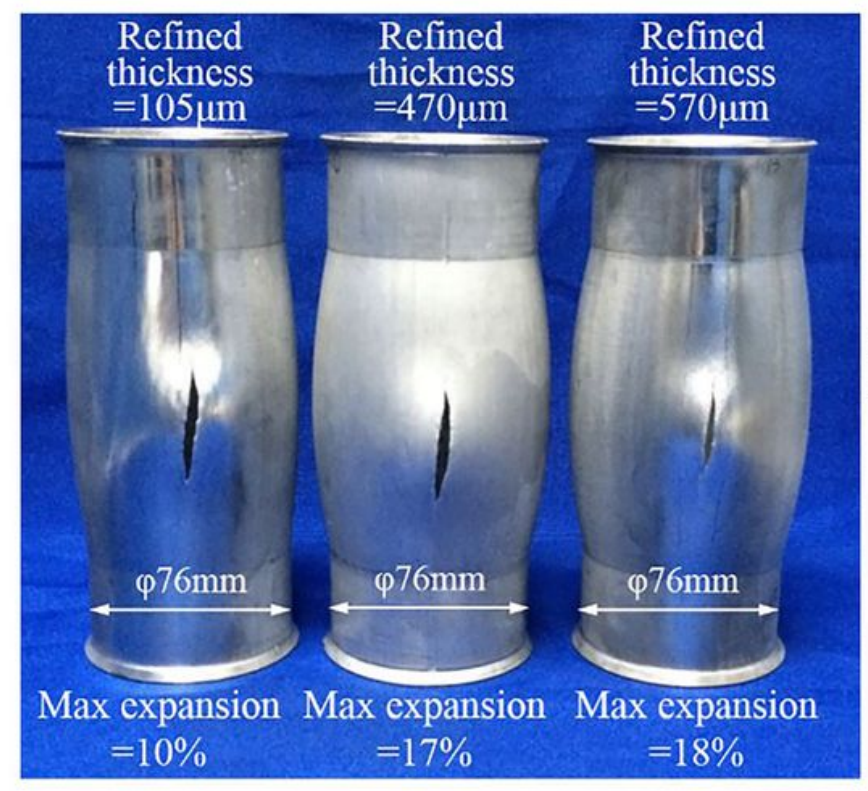

(a) Bulged tubes

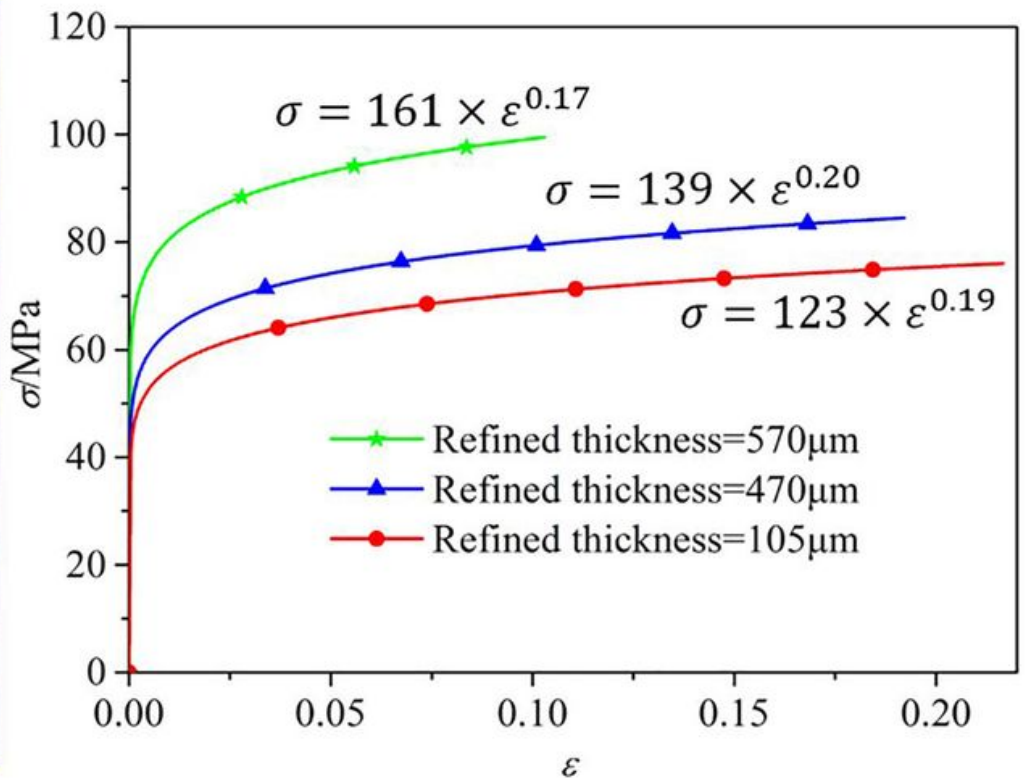

(b) Stress-strain curves

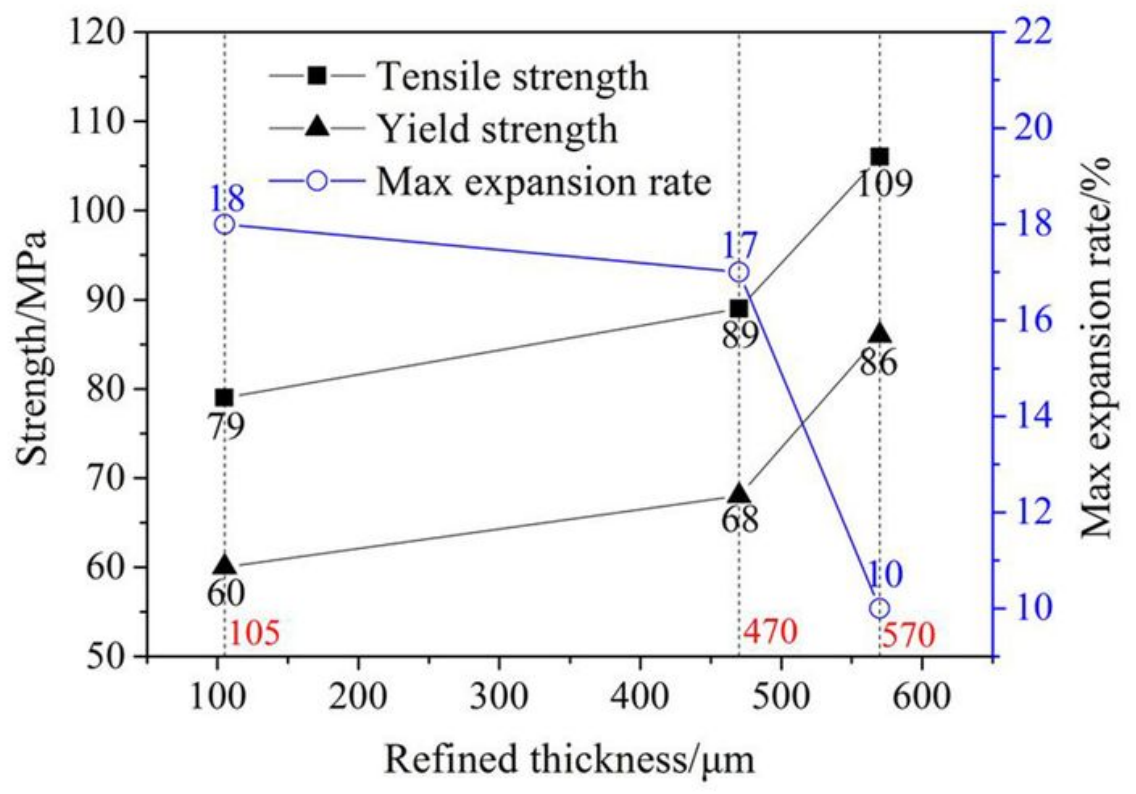

(c) Effect of normal gradient grain on the mechanical properties

\section{Figure 3}

Bulged tubes with normal gradient grain and mechanical properties. 

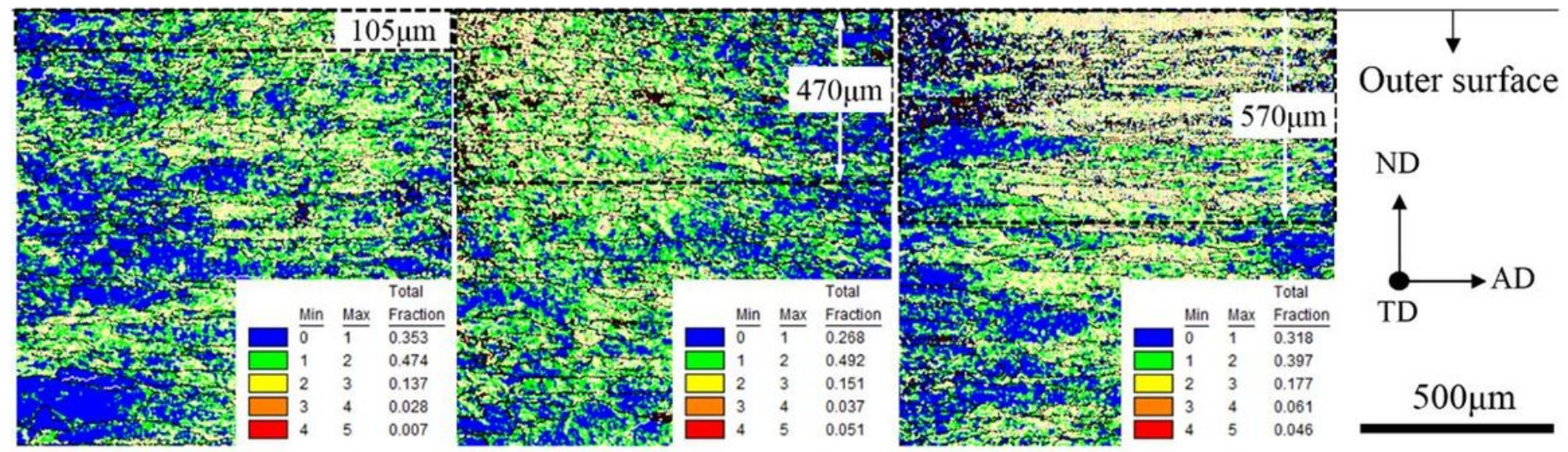

(a) Refined thickness $=105 \mu \mathrm{m}$;

(b) Refined thickness $=470 \mu \mathrm{m}$;

(c) Refined thickness $=570 \mu \mathrm{m}$;

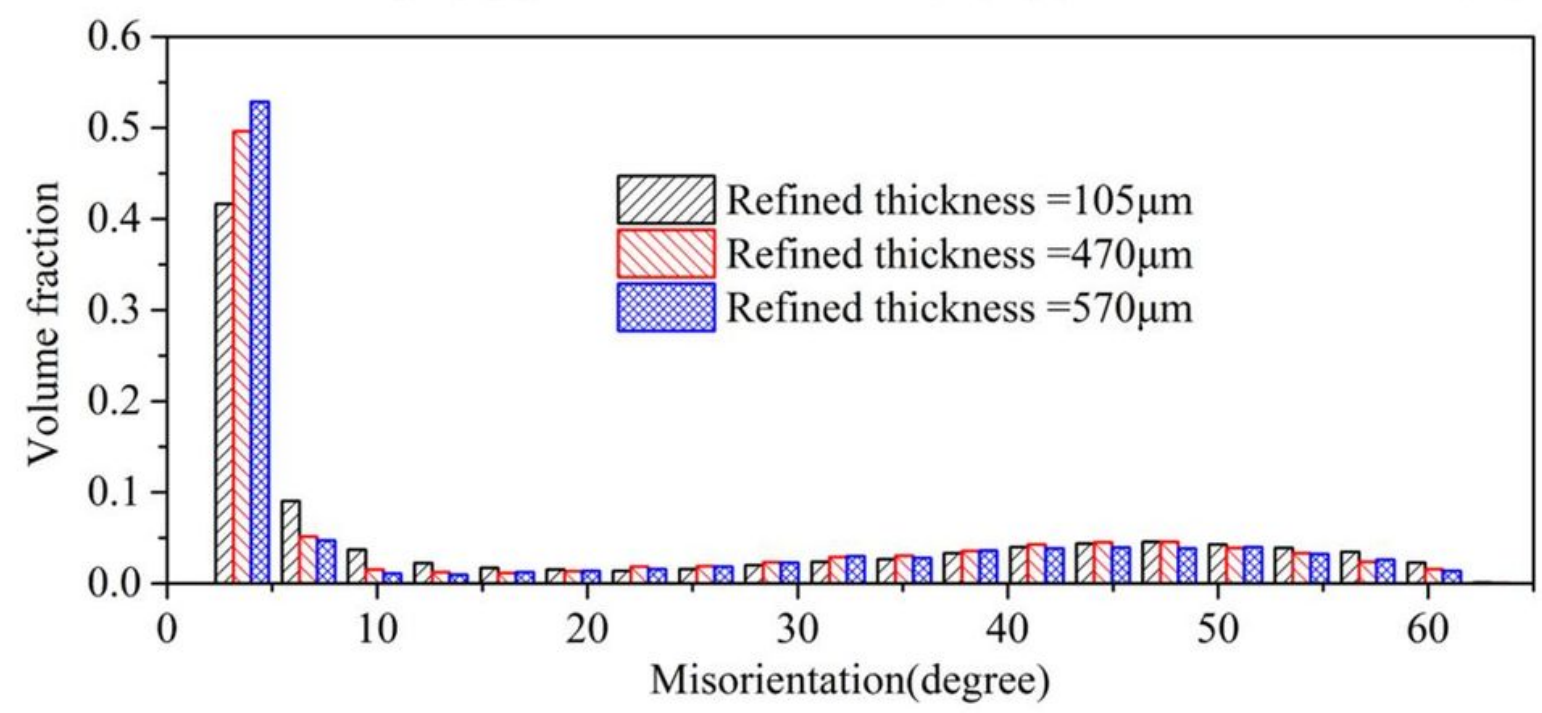

(d) Misorientation angle distributions

Figure 4

Kernel average misorientation (KAM) and distribution of misorientation $(\varepsilon=12 \%)$. 